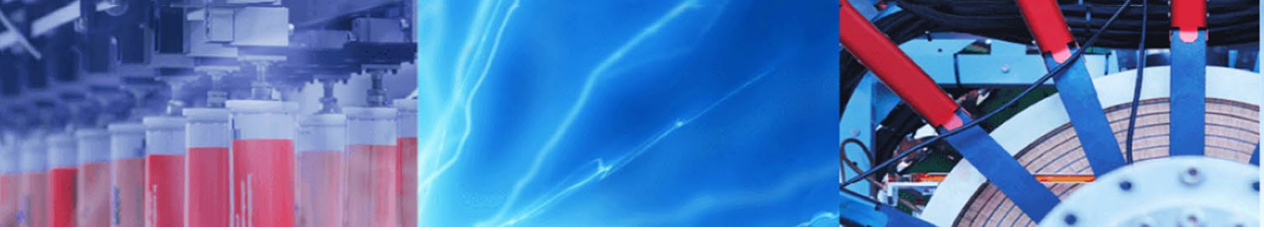

Research Article

\title{
Synthesis of highly electrically conductive and electrochemically stable porous boron-doped carbon microspheres
}

\author{
Anima B. Bose ${ }^{1,2} \cdot$ Junbing Yang ${ }^{3} \cdot \mathrm{Wei}_{\mathrm{Li}^{1,2}}$
}

() Springer Nature Switzerland AG 2019

\begin{abstract}
Corrosion resistant carbon with enriched electrical conductivity is advantages for long lasting electrochemical device development. In this study, boron-doped carbon microspheres (BCMS) were prepared by a chemical vapor deposition process from $p$-xylene and boron trichloride, followed by a mild oxidation step to alter their surface properties and pore structure. XPS study confirmed the formation of the BCMS with a B:C nominal ratio of 1:10.9. Morphological study illustrated the formation of smooth BCMS microspheres with uniform distribution with an average diameter 0.5-1.0 $\mu \mathrm{m}$. $\mathrm{N}_{2}$ sorption measurements revealed that as synthesized BCMS has a pore structure of less than $2 \mathrm{~nm}$ with a maximum distribution around $0.4 \mathrm{~nm}$ and a surface area of $213 \mathrm{~m}^{2} \mathrm{~g}^{-1}$. Compared to the traditionally used Vulcan XC-72 in polymer electrolyte membrane fuel cells and reversible fuel cells, the BCMS material has similar pore structure and surface area but exhibits higher electrochemical stability. BCMS also exhibits excellent low electrical resistivity $\left(37.2 \Omega \mathrm{sq}^{-1}\right)$ and thermal stability (up to $400^{\circ} \mathrm{C}$ ) as carbon nanotubes. These superior properties suggest that the BCMS is a very promising candidate as supports for electrocatalysts in electrochemical devices, such as polymer electrolyte membrane fuel cells, reversible fuel cells, lithium-air batteries, etc.
\end{abstract}

Keywords Nano-porous microsphere - Boron-doped carbon · Chemical-vapor-deposition - Electrically conductive . Thermal stability

\section{Introduction}

During the past two decades, tremendous efforts have been made in developing various geometric shaped carbon-based micro/nanostructured materials for a wide range of applications including energy devices. Among different shapes of carbon materials, spheres, tubes, fibers/ wires, flasks, etc., spherical particles pose utmost benefits over others in uniform packaging [1-4]. Carbon spheres are thus receiving enormous attention in electrochemical energy conversion and energy storage device development. Electrocatalysts are deemed as the heart of many electrochemical systems, and electrocatalyst supports play a vital role in achieving high performing device development such as various type of fuel cells, lithium-air batteries, anode materials in lithium-ion batteries, sulphur host in lithium-sulphur batteries, electrode materials in supercapacitors, and many others applications [5-12]. In fact, carbon based materials remain the most effective electrocatalyst in highly demanding chemical and electrochemical environments. For example, in polymer electrolyte membrane fuel cells (PEMFC), carbon support highly influence on enduring nano-structured catalyst for

Electronic supplementary material The online version of this article (https://doi.org/10.1007/s42452-019-0217-x) contains supplementary material, which is available to authorized users.

$\triangle$ Anima B. Bose, abbose@uh.edu; $\bowtie$ Junbing Yang, jbyang@hotmail.com | 1 Department of Engineering Technology, The University of Houston, Houston, TX 77204, USA. ${ }^{2}$ Texas Center for Superconductivity, The University of Houston, Houston, TX 77204, USA. ${ }^{3}$ California Lithium Battery, Los Angeles, CA 90013, USA.

SN Applied Sciences (2019) 1:206 | https://doi.org/10.1007/s42452-019-0217-x

Received: 12 November 2018 / Accepted: 24 January 2019 / Published online: 4 February 2019 
redox reductions without getting corroded of the sluggish electrode-kinetics.

It is generally expected that electrode materials and electrocatalyst supports must propound essential properties as high electrical conductivity, high electrochemical stability, competent to generate appropriate pore structure from a standpoint of effectiveness. In addition to the high electrical conductivity, foreseeable electrode materials are required to minimize internal electrical resistance, reduce ohmic over potential and thus improve the performance of the electrochemical devices. In general, electrochemically stable catalyst support has a great deal of influences on the durability of the electrochemical devices. For instance, carbon oxidation causes effective surface area loss in PEMFCs, one of the major factors resulting in the degradation of the cathodes leading to unfortunate aggregation of nano-catalysts and the structural failures of electrodes [13-15]. It is well established that carbon material used in the electrodes at a high electrode potential, such as the cathodes of PEMFCs, reversible fuel cells, lithium-air batteries, is subject to severe deterioration and needs electrochemically stable noble conducting materials for electrochemical device development [10, 13-16]. Undoubtedly, the pore size and surface area play key roles when carbon is used as electrocatalyst supports in an electrochemical device with solid electrolyte, such as PEMFCs, where the pores of the carbon spheres should not be larger than the catalyst nanoparticle with typical size about 3-5 $\mathrm{nm}$ to avoid nanoparticles entering the pores, which significantly reduces the catalyst utilization efficiency lacking from three-phase boundary for protons conduction $[16,17]$. Whereas in the cathodes of lithium-air batteries, the carbon spheres should have large pores to accommodate the catalyst nanoparticles and the solid $\mathrm{Li}_{2} \mathrm{O}_{2}$ product from the charging process [18]. Above few examples validate that pore structure and surface area of supporting materials does vary depending on device while other collective properties persist.

Globally, significant efforts have been devoted to evolving boron/nitrogen doping into carbon materials, which have been known to change the physical and chemical properties of carbon. Intensive attention in recent years has been given to improve such properties, i.e., electrical conductivity, corrosion resistance by doping boron/ nitrogen into carbon materials to meet the state-of-theart requirements of their applications [19-25]. In principle, carbon materials hold good electrical conductivity owing to the delocalized $\pi$-electron throughout the covalently bonded carbon network created by $s p^{2}$ hybridized orbitals. Boron is an ideal doping agent due to its electronic compatibility and configuration of $s p^{2}$ hybridized orbitals, thus forming a covalent bonding network with neighboring carbons. Besides, the presence of a vacant pr orbital to effectively engage in $\pi$-electron delocalization that primarily contributes to the electrical conductivity. Studies also show that boron is a unique and efficient dopant for improving the oxidation resistance of graphite, carbon fibers, carbon/carbon composites, carbon nanotubes and various other carbon materials $[26,27]$. However, it needs to be noted that the improvements of the properties usually depend on the percentage of B-dopant. For instance, Mondal et al. [16] demonstrated two order conductivity drop in boron-doped carbon microsphere compared to the un- doped microspheres.

Carbon spheres with customized properties are advantageous over many geometric structures, and have been prepared in many routes, such as templating $[9,10]$, pyrolysis [11,28], reduction [29], and chemical vapor deposition (CVD) [30]. Compared with the many studies on borondoped carbon nano-tubes, boron doping of spherically shaped carbon materials have not yet provoked much study. In this report, we present a synthesis protocol for preparing boron-doped carbon microspheres through a CVD process that allows controlled tuning of the size and doping amount. A two-step process involved in material synthesis is presented here: (1) grow nanoporous borondoped carbon microspheres and (2) open the porous structure via mild oxidation. The obtained properties, such as pore structure, electrical conductivity, thermal stability and electrochemical oxidation of BCMS were compared with other carbon based materials such as carbon nanotubes, and traditional catalyst support material, Vulcan XC-72 for PEMFCs and reversible fuel cells (RFCs). The results discussed in this report evidently advocate that the $\mathrm{BCMS}$ is a highly promising candidate as catalyst supports for electrocatalysts development of PEMFCs, RFCs, lithiumair batteries and other electrochemical devices.

\section{Experimental}

\subsection{Synthesis and activation}

BCMS were prepared using a CVD process inside a quartz tube inserted through a low-temperature heating section (Zone $\mathrm{I}, 200^{\circ} \mathrm{C}$ ) and a high-temperature heating section (Zones II, $950^{\circ} \mathrm{C}$ ). $0.34 \mathrm{~g}$ ferrocene (Sigma-Aldrich) was dissolved in $23.6 \mathrm{~g}$ boron trichloride solution in $\mathrm{p}$-xylene (1.0 M, Sigma-Aldrich) and used as the precursor for BCMS synthesis. It was injected at rate of $2 \mathrm{~mL} / \mathrm{min}$ and vaporized in the quartz tube at Zone I. The vapor was transported to Zone II by a mixture of $\mathrm{H}_{2}$ and $\mathrm{Ar}$ gases at flow rates of 60 and $90 \mathrm{~mL} \mathrm{~min}^{-1}$, respectively. The BCMS was grown on a polished quartz plate inside the quartz tube at Zone II. After $30 \mathrm{~min}$, the solution injection was stopped, and the furnaces were turned off and naturally cooled down 
to room temperature maintaining the flow of $\mathrm{H}_{2}$ and $\mathrm{Ar}$ gases at the same flow rate as was during synthesis.

In the second step of synthesis; as-synthesized BCMS was activated by a mild oxidation in water steam to open the pore structure. For this phase of synthesis, Zone I and Zone II were kept at 500 and $850^{\circ} \mathrm{C}$, respectively. Deionized water was injected at the rate of $0.225 \mathrm{~mL} \mathrm{~min}{ }^{-1}$ into and evaporated inside the quartz tube in the middle of Zone I. The steam was carried by flowing Ar gas at $140 \mathrm{~mL} \mathrm{~min}^{-1}$ to Zone II to react with the BCMS synthesized in the step 1. The injection of water continued for 30 min before cooling the furnaces to room temperature under inert environment before collect the product.

\subsection{BCMS characterization}

The boron to carbon ratio $(B: C)$ of the activated $B C M S$ sample was evaluated using X-ray photo-electron Spectroscopy (XPS, Kratos AXIS-165) equipped with a monochromatic AI Ka X-ray source. The morphology and microstructure of the activated BCMS sample were examined on a scanning electron microscope (SEM, Hitachi S-4700) operated at $10 \mathrm{kV}$. Energy-dispersive X-ray spectroscopy (EDS/EDX) was performed at $10 \mathrm{kV}$ to determine the bulk composition of the activated BCMS microspheres. Thermogravimetric analysis (TGA) experiments were performed on Shimadzu, TGA-50 with a 10-12 mg sample in air at a heating rate of $10{ }^{\circ} \mathrm{C} \mathrm{min}^{-1}$. Surface area and pore-size distribution of the activated BCMS sample were characterized with $\mathrm{N}_{2}$ sorption measurements on an automated Micromeritics ASAP 2010 sorption analyzer at $77 \mathrm{~K}$ and determined by means of Brunauer-Emmett-Teller (BET) method and Horvath-Kawazoe (HK) model, respectively. Prior to surface area and pore-size analysis, the sample was degassed (vacuum-degassed) at $120^{\circ} \mathrm{C}$ for $4 \mathrm{~h}$. The BET equation was used to calculate the surface area [31]. Fourpoint-probe method was adopted to measure the sheet resistance of the activated BCMS on the original quartz substrate. $B C M S$ resistance data was then compared with the carbon nanotubes (CNT, hollow structure multi-wall carbon nanotubes, $30 \mathrm{~nm}$ in diameter, 1-5 $\mu \mathrm{m}$ in length, PD30L1-5, NanoLab) in a compressed state.

\subsection{Electrochemical evaluation}

The electrochemical performances of the activated BCMS were evaluated through cyclic voltammetry (CV) experiments conducted with a potentiostat $(\mathrm{CHI} 1140 \mathrm{~A})$ in a three-electrode configuration: a Pt wire as the counter electrode, a glassy carbon rotating disk electrode (RDE, $5 \mathrm{~mm}$ diameter, Pine instrument) as the working electrode, and $\mathrm{Ag} / \mathrm{AgCl}$ (sat. $\mathrm{KCl}$ ) as the reference electrode. An Ar saturated $0.10 \mathrm{M} \mathrm{HClO}_{4}$ was used as electrolyte in this study.
Carbon inks (2.0 $\left.\mathrm{mg} \mathrm{mL}^{-1}\right)$ made of BCMS, CNT and Vulcan XC-72 were prepared separately by well dispersing the carbon into a 1:5 deionized water/isopropanol mixture. The sample loading on a freshly polished mirror-like RDE tip was $20.0 \mu \mathrm{g}$ and was cycled between $0-1.2 \mathrm{~V}$ versus $\mathrm{Ag} /$ $\mathrm{AgCl}$ at a scan rate of $50 \mathrm{mV} \mathrm{s}^{-1}$.

\section{Results and discussion}

BCMS in this study were prepared from a reactant mixture of a boron source (boron trichloride), carbon sources ( $p$-xylene, xylene), and a catalyst (ferrocene) on a quartz slide by a CVD process. The present study distinctly focused on understanding the causes behind the formation of conductive porous BCMS microspheres, as well as how the boron doping affect the electrical conductivity and its oxidation resistance of the BCMS.

The molecular structure of the precursor(s) and the synthesis environment enfolds a crucial effect on carbon network. The synthesis of highly pure conductive BCMS was carried out via a two-step process: (1) in the first step pyrolysis of xylene was done in the vapor-phase; and followed by (2) the steam activation for tailoring the BCMS in high purity texture. Fundamentally, hydrocarbon vapor separate hydrogen by dissolving carbon in hot metal iron of ferrocene at a relatively high temperature of $950^{\circ} \mathrm{C}$ and precipitated out as a sphere, BCMS. Ferrocene participated in this synthesis as a catalyst, at this operating temperature also as a second source of hydrocarbon and provided the stronger adhesion to the growing carbon network. At this highly reducing atmosphere, cyclic hydrocarbon first separate out and intend to curve to bridge inside to form carbon sphere [32]. It can be theorized that at above $700{ }^{\circ} \mathrm{C}$ xylene might separate when $\mathrm{Fe}^{2+}$ catalyst reduced by aliphatic ligand of xylene, and in order to minimize the interfacial energy, the clusters rearrange themselves in simultaneous delocalization of $\pi$ electrons of carbon. Though, morphology of BCMS is greatly impacted by the aromatic structure of carbon sources xylene and ferrocene, but iron to carbon ratio in the range $0.016-0.033$ range contribute to spheres formation and pore-size structure [33]. The remaining iron of first step synthesized BCMS was removed through partial oxidation occurred during second step of synthesis. The steam activation at $850^{\circ} \mathrm{C}$ is assisted to remove portion of the impurities including amorphous carbon and residual Iron of ferrocene, which helps to create porous structure inside the carbon microspheres [33].

It is well understood, incorporating boron into carbon changes the physicochemical properties of carbon materials such as the surface energy, conductivity and ferromagnetic properties. The carbon oxidation can be 
Table 1 Quantification analysis of the XPS spectrum of the activated $B C M S$ with a nominal $B / C$ atomic ratio of $1: 10.9$

\begin{tabular}{lllcrc}
\hline Peak & Position (eV) & FWHM (eV) & Raw area (CPS) & RSF & $\begin{array}{l}\text { Atomic } \\
\text { ratio } \\
(\%)\end{array}$ \\
\hline B 1s & 191.0 & 4.2 & 8630.1 & 0.16 & 7.5 \\
C 1s & 284.0 & 3.2 & $165,112.6$ & 0.28 & 81.5 \\
O 1s & 532.0 & 3.5 & $62,512.7$ & 0.78 & 11.0 \\
\hline
\end{tabular}

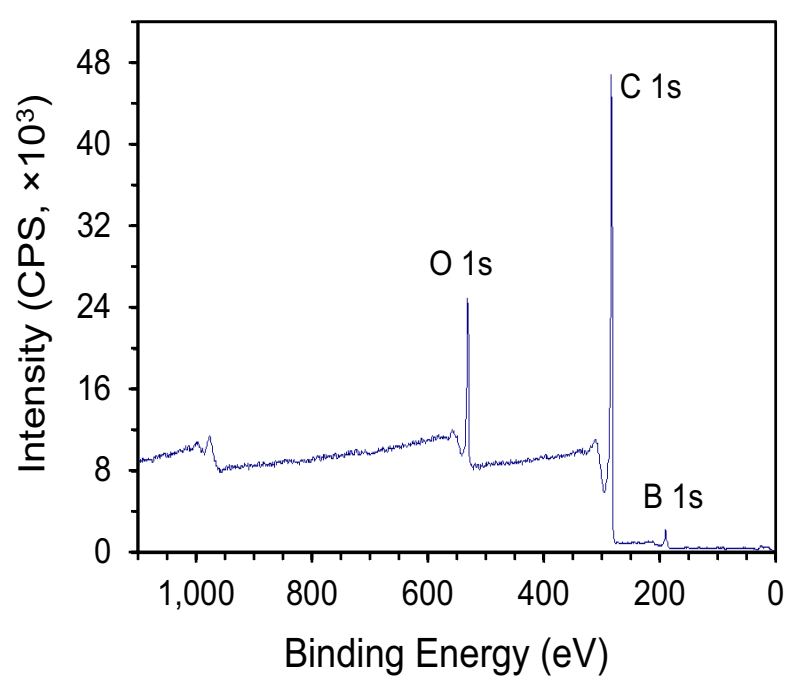

Fig. 1 XPS spectrum of the activated BCMS with a B/C nominal atomic ratio of 1:10.9

minimized by incorporating boron in carbon lattice and substitution in the graphitic lattice effectively happens when boron content below one atomic percent $[3,14,16$, $34,35]$. XPS attained atomic ratio of boron to carbon (B:C) of the activated BCMS is 1:10.9. The analysis displays that product consists of $7.5 \% \mathrm{~B}, 81.5 \% \mathrm{C}$ and $11.0 \% \mathrm{O}$ as listed in Table 1 ; indicates the effective boron doping occurred in the process. Figure 1 presents the XPS characterized peaks position of BCMS composition; B $1 \mathrm{~s}, \mathrm{C} 1 \mathrm{~s}$, and $\mathrm{O} 1 \mathrm{~s}$ are at 191, 284 and $532 \mathrm{eV}$, respectively. Figure 1 shows the $\mathrm{B} 1 \mathrm{~s}$ peak at $191 \mathrm{eV}$ which should have been at $188 \mathrm{eV}$ for pure boron; evident the boron bondage to carbon network, i.e., boron partially substitutes carbon into the $s p^{2}$ carbon plane. The oxygen presence in the BCMS analysis is mainly from the surface oxidation of carbon during the steam activation process, in which some carbon was oxidized into active functional groups containing oxygen in the process [36]. The bulk composition of the activated BCMS showed a Boron to Carbon atomic ratio between $1: 7.3$ and $1: 10.2$, matching relatively well with the ratio from XPS ( $B / C$ nominal atomic ratio $=1: 10.9)$. The Boron to carbon ratio obtained through EDX analysis are included in the supporting information (Figure S1 and Table S1).

Carbon materials generally possess good electrical conductivity and various studies have proven that electron deficient or acceptor boron dopant in carbon network can further enhance the electronic conductivity of carbon when $B / C$ ratio below $0.5[35,37,38]$. According to analyzed data of $B C M S$ microspheres, the $B / C$ value of $B C M S$ is 0.092 , distinctly even far lower than 0.5 reported range. The four-point-probe sheet resistance of the activated BCMS microspheres measured of $37.2 \Omega \mathrm{sq}^{-1}$ agrees with the boron carbon ratio on electrical conductivity stated above, which is lower than the CNT $\left(57.6 \Omega \mathrm{sq}^{-1}\right)$ though the packing states of both samples were slightly different. The four-point-probe testing was done at room temperature for both samples. The enhanced electrical conductivity results from boron bonding through $s p^{2}$ network of carbon that expected to increase the density of free charge carriers, thus increases the electrical and thermal conductivity. The obtained BCMS microspheres hypothetically could be an excellent candidate for electrically conductive material and would be very appropriate supports for electrocatalysts in electrochemical devices.

SEM images of the activated BCMS sample in Fig. 2 exhibit uniform distribution of smooth spheres without any tiny fragments attached. As mentioned above the steam activation at $850{ }^{\circ} \mathrm{C}$ is assisted to remove impurities including amorphous carbon and residual Iron of ferrocene. The estimated diameter of pure BCMS are in the range of $0.5-1.0 \mu \mathrm{m}$, which is larger than
Fig. 2 a Low magnification and $\mathbf{b}$ high magnification SEM images of the activated BCMS with a B/C nominal atomic ratio of 1:10.9
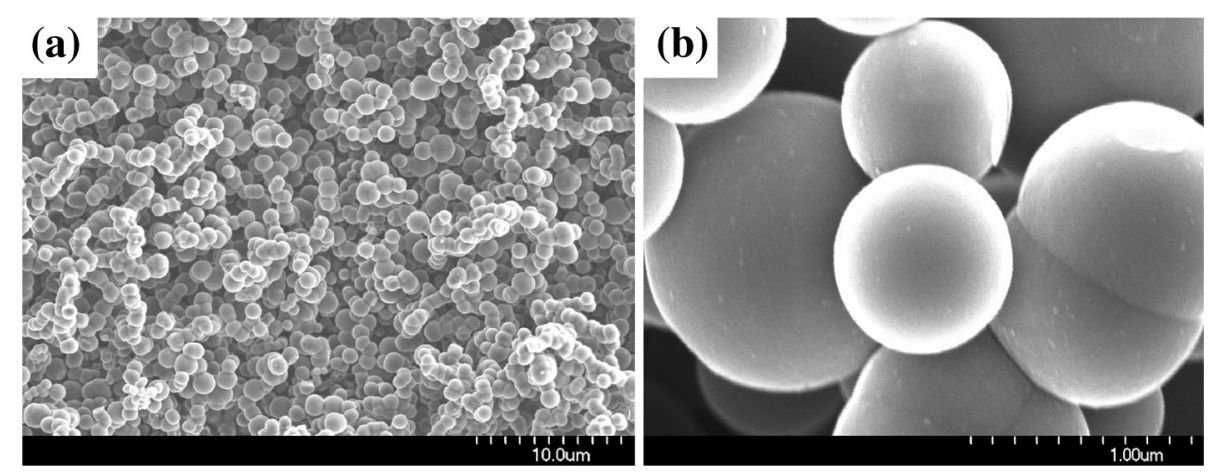
carbon nanospheres (100-150 nm) prepared from sucrose through a non-catalytic hydrothermal route [39], but smaller than other carbon microspheres (1-7 $\mu \mathrm{m})$ [40-42]. The uniform shape and size, and clean and smooth surface certainly would benefit in uniformly packing the sample particles for preparing electrodes with a uniform pore structure in fabricating electrode for electrochemical device design [1].

Surface area and porosity are critical parameters of carbon materials especially as supports for catalysts of electrochemical devices. The increase of surface area can be achieved through a special treatment, i.e., in this study partial oxidation was employed to increase the porosity and surface area of the BCMS microspheres. The activated microspheres is presumed to have an openedand-enlarged porous structure, which was achieved by evaporating steam at a relatively low temperature gradient without disturbing the sample matrix that prepared in first step of synthesis. Figure 3 shows the $\mathrm{N}_{2}$ adsorption-desorption isotherm and pore-size distribution of the activated $\mathrm{BCMS}$ microspheres with a $\mathrm{B} / \mathrm{C}$ atomic ratio
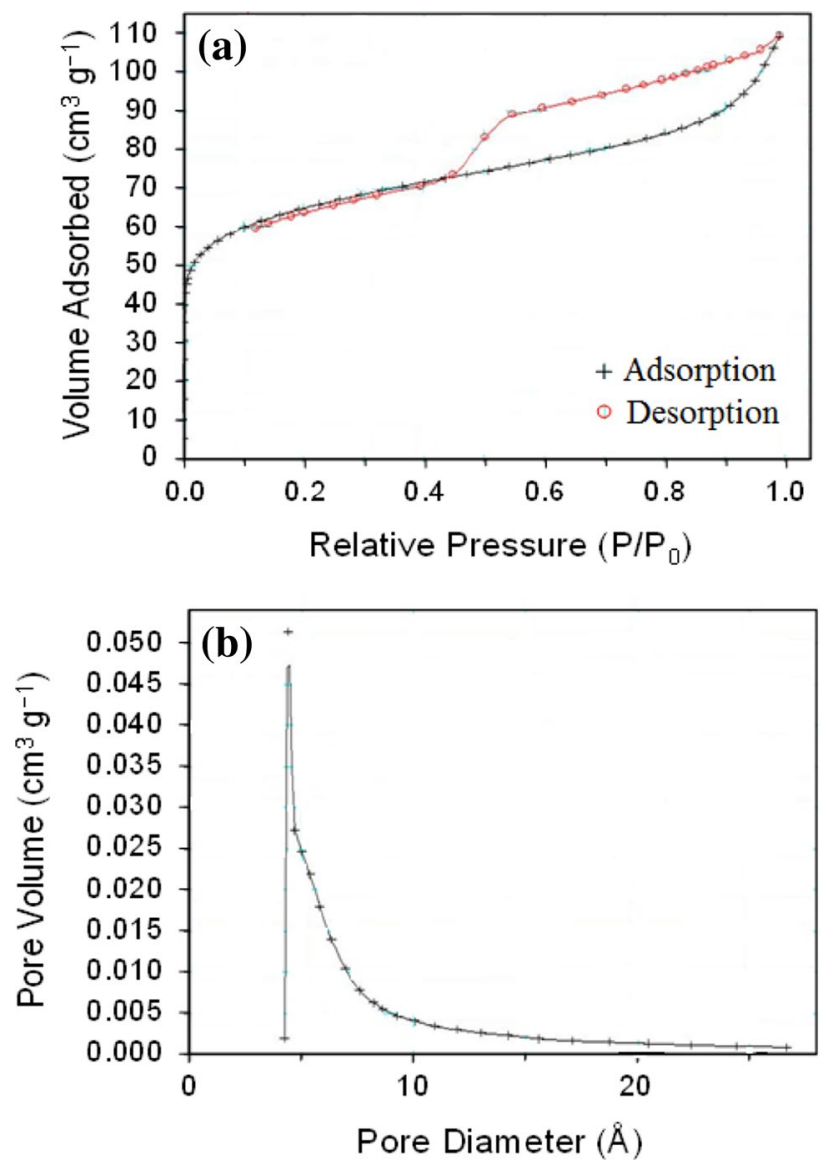

Fig. 3 a Nitrogen adsorption-desorption isotherm and b HorvathKawazoe differential pore volume plot of the activated BCMS with a $\mathrm{B} / \mathrm{C}$ nominal atomic ratio of 1:10.9 of 1:10.9. The isotherm in Fig. $3 a$ can be analogous to IUPAC (International Union of Pure and Applied Chemistry) type I physisorption isotherm with type $\mathrm{H} 4$ hysteresis loop, which is indicative of the existence of narrow slit-like microspores and the connectivity of inside pores [43]. The pore-size distribution in Fig. $3 \mathrm{~b}$ derived from HK method shows that most of pores are in the range of $<2 \mathrm{~nm}$ in size with a maximum distribution around $0.4 \mathrm{~nm}$, verifying that the activated BCMS is microporous. The BET surface area $\left(S_{B E T}\right)$ of the microspheres obtained from the isotherm experiment is $213 \mathrm{~m}^{2} \mathrm{~g}^{-1}$, which is very close to that of a commonly used carbon black (Vulcan XC-72, $250 \mathrm{~m}^{2} \mathrm{~g}^{-1}$ ) [44] and within the range of multi-wall carbon nanotubes (MWCNT, between 60 and $250 \mathrm{~m}^{2} \mathrm{~g}^{-1}$ ) reported in the literature [45]. Considering the similar pore size and surface area to Vulcan XC-72, the activated BCMS is an appropriate candidate for supporting nano-sized electrocatalysts for a wide range of applications including electrochemical device development.

Carbon materials are susceptible to microstructural and morphological degradation under oxidizing conditions in the electrodes with a high electrode potential $[14,15,17]$. In addition to the mechanistic explanation given above, the oxidation stability and corrosion resistance were tested further by using TGA and cyclic voltammetry experiments, respectively. The activated BCMS microspheres exhibit a very comparable oxidation stability or thermal stability to CNT via TGA as shown in Fig. 4. With the evidences in the literature that CNT has better thermal stability than Vulcan XC-72, it is reasonable to conclude that the BCMS is qualified in thermal stability as support for electrocatalysts in fuel cells and other electrochemical devices.

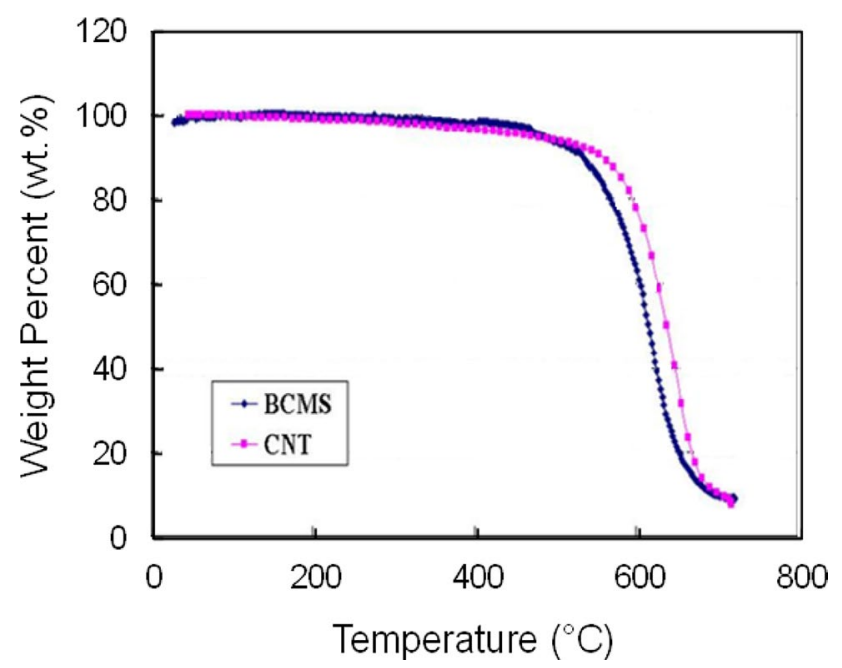

Fig. 4 Comparison of thermal stability by TGA measurements of the activated $B C M S$ with a $B / C$ nominal atomic ratio of $1: 10.9$ and the commercial CNT 
The corrosion resistances of different carbon materials are usually studied by electrochemical characterization $[14,17]$. Furthermore, BCMS microsphere has been tested and compared at the onset potentials and currents of the oxidation wave of the cyclic voltammograms in $0.10 \mathrm{M} \mathrm{Ar}$ saturated $\mathrm{HClO}_{4}$. Higher onset potential and lower oxidation current signify a better corrosion resistance of activated BCMS shown in Fig. 5 compared to XC-72 carbon and CNT. The voltammogram in Fig. 5 reveals an oxidation peak at ca. $0.4 \mathrm{~V}$ of XC-72 carbon and oxidation starting ca. $0.7 \mathrm{~V}$. The oxidation peak and curve are, respectively, attributed to the oxidation of surface oxides on XC-72 carbon and the oxidation of carbon itself, i.e., carbon corrosion [34]. A similar voltammogram is observed for the CNT (Fig. 5) indicates a similar oxidation peak but a different oxidation curve with a higher onset potential (ca. $1.0 \mathrm{~V}$ ) but smaller current. Voltammogram does not show oxidation peak at ca. $0.4 \mathrm{~V}$ for BCMS, which suggests no detectable surface oxides for BCMS. The current in that particular region is actually capacitive current of the electrode. The electrochemical study suggests that the both BCMS and CNT assimilate comparable corrosion behavior and possess better electrochemical stability than XC-72 carbon in acidic media. It has been recognized and possible reasoning given by various researchers that boron doping of carbon improves the crystallinity $[16,17,34]$. Thus boron doped carbon frame decreases the total number of accessible carbon site for oxygen and expected to form a barrier layer, $\mathrm{B}_{2} \mathrm{O}_{3}$ during oxidation above $450{ }^{\circ} \mathrm{C}$ $[43,46]$. Based on obtained result of pure BCMS microsphere prepared at $950^{\circ} \mathrm{C}$ followed by partial oxidation process, the rational explanation for oxidation and thermal stability would be the following. The existence of boron

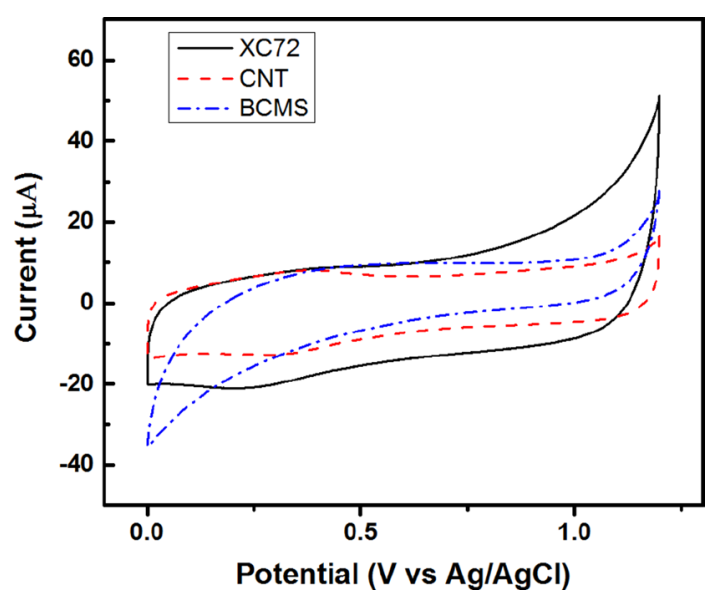

Fig. 5 Cyclic voltammograms of a XC-72 carbon black, b CNT, and c activated $B C M S(B / C$ nominal atomic ratio $=1: 10.9)$ in $0.1 \mathrm{M} \mathrm{HClO}_{4}$ saturated with Ar gas. The potential scanning rate is $50 \mathrm{mV} \mathrm{s}^{-1}$ increases the activation energy for the $\mathrm{C}-\mathrm{O}_{2}$ reaction; restrict $\mathrm{CO}$ chemical decomposition via electron transfer between carbon and substitutional boron; in fact acts as a catalyst $[26,47]$.

\section{Conclusions}

Corrosion resistant carbon with enriched electrical conductivity is advantages for long lasting electrochemical device development. In this study, boron-doped carbon microspheres (BCMS) were prepared by a chemical vapor deposition (CVD) process from $p$-xylene and boron trichloride, followed by a mild oxidation step to alter their surface properties and pore structure. XPS confirmed the formation of the BCMS with a $\mathrm{B}: \mathrm{C}$ nominal ratio of 1:10.9. Morphological study illustrated the formation of smooth BCMS microspheres with uniform distribution with an average diameter $0.5-1.0 \mu \mathrm{m} . \mathrm{N}_{2}$ sorption measurements revealed that as synthesized BCMS has a pore structure of less than $2 \mathrm{~nm}$ with a maximum distribution around $0.4 \mathrm{~nm}$ and a surface area of $213 \mathrm{~m}^{2} \mathrm{~g}^{-1}$. Compared to the traditionally used Vulcan XC-72 in polymer electrolyte membrane fuel cells (PEMFC) and reversible fuel cells, the BCMS material has similar pore structure and surface area but exhibits higher electrochemical stability. BCMS also exhibits excellent low electrical resistivity $\left(37.2 \Omega \mathrm{sq}^{-1}\right)$ and thermal stability (up to $400^{\circ} \mathrm{C}$ ) as carbon nanotubes. These superior properties suggest that the BCMS is a very promising candidate as supports for electrocatalysts in electrochemical devices, such as polymer electrolyte membrane fuel cells, reversible fuel cells, lithium-air batteries, etc.

Acknowledgements The authors are grateful to the U.S. Department of Transportation (IL 26-7006), University of Houston, and Texas Center for Superconductivity at the University of Houston for the support of this work. We appreciate the collaboration of Chemical Sciences and Engineering Division of Argonne National Laboratory and their facilities for part of the data generation. We also thank Dr. Xinwei Cai and Dr. Rajesh Sahadevan for their technical assistance in manuscript preparation.

\section{Compliance with ethical standards}

Conflict of interest The authors declare no conflict of interest.

\section{References}

1. lijima S (1991) Helical microtubules of graphitic carbon. Nature 354:56. https://doi.org/10.1038/354056a0

2. Rana RK, Gedanken A (2002) Carbon nanoflask: a mechanistic elucidation of its formation. J Phys Chem B 106(38):9769-9776. https://doi.org/10.1021/jp025566j

3. Vander Wal RL, Ticich TM, Curtis VE (2000) Directed synthesis of metal-catalyzed carbon nanofibers and graphite encapsulated 
metal nanoparticles. J Phys Chem B 104(49):11606-11611. https ://doi.org/10.1021/jp002025q

4. Yang J-B, Ling L-C, Liu L, Kang F-Y, Huang Z-H, Wu H (2002) Preparation and properties of phenolic resin-based activated carbon spheres with controlled pore size distribution. Carbon 40(6):911-916. https://doi.org/10.1016/S0008-6223(01)00222-6

5. Dresp S, Luo F, Schmack R, Kühl S, Gliech M, Strasser P (2016) An efficient bifunctional two-component catalyst for oxygen reduction and oxygen evolution in reversible fuel cells, electrolyzers and rechargeable air electrodes. Energy Environ Sci 9(6):2020-2024. https://doi.org/10.1039/C6EE01046F

6. Etacheri V, Wang C, O'Connell MJ, Chan CK, Pol VG (2015) Porous carbon sphere anodes for enhanced lithium-ion storage. J Mater Chem A 3(18):9861-9868. https://doi.org/10.1039/C5TA01360G

7. Liu J, Choi HJ, Meng L-Y (2018) A review of approaches for the design of high-performance metal/graphene electrocatalysts for fuel cell applications. J Ind Eng Chem 64:1-15. https://doi. org/10.1016/j.jiec.2018.02.021

8. Park CS, Kim KS, Park YJ (2013) Carbon-sphere/ $\mathrm{Co}_{3} \mathrm{O}_{4}$ nanocomposite catalysts for effective air electrode in Li/air batteries. J Power Sour 244:72-79. https://doi.org/10.1016/j.jpows our.2013.03.153

9. Roberts AD, Li X, Zhang $\mathrm{H}$ (2014) Porous carbon spheres and monoliths: morphology control, pore size tuning and their applications as Li-ion battery anode materials. Chem Soc Rev 43(13):4341-4356. https://doi.org/10.1039/C4CS00071D

10. Sohn H, Gordin ML, Xu T, Chen S, Lv D, Song J, Manivannan A, Wang D (2014) Porous spherical carbon/sulfur nanocomposites by aerosol-assisted synthesis: the effect of pore structure and morphology on their electrochemical performance as lithium/ sulfur battery cathodes. Acs Appl Mater Inter 6(10):7596-7606. https://doi.org/10.1021/am404508t

11. Xiong W, Liu M, Gan L, Lv Y, Li Y, Yang L, Xu Z, Hao Z, Liu H, Chen $L$ (2011) A novel synthesis of mesoporous carbon microspheres for supercapacitor electrodes. J Power Sourc 196(23):1046110464. https://doi.org/10.1016/j.jpowsour.2011.07.083

12. Theerthagiri J, Durai G, Karuppasamy K, Arunachalam P, Elakkiya V, Kuppusami P, Maiyalagan T, Kim H-S (2018) Recent advances in 2-D nanostructured metal nitrides, carbides, and phosphides electrodes for electrochemical supercapacitors: a brief review. J Ind Eng Chem. https://doi.org/10.1016/j.jiec.2018.06.038

13. Nguyen T-A, Lee S-W (2018) Bulky carbon layer inlaid with nanoscale $\mathrm{Fe}_{2} \mathrm{O}_{3}$ as an excellent lithium-storage anode material. J Ind Eng Chem. https://doi.org/10.1016/j.jiec.2018.07.038

14. Wang J, Yin G, Shao Y, Zhang S, Wang Z, Gao Y (2007) Effect of carbon black support corrosion on the durability of Pt/C catalyst. J Power Sourc 171(2):331-339. https://doi.org/10.1016/j. jpowsour.2007.06.084

15. Wilson MS, Garzon FH, Sickafus KE, Gottesfeld S (1993) Surface area loss of supported platinum in polymer electrolyte fuel cells. J Electrochem Soc 140(10):2872-2877. https://doi. org/10.1149/1.2220925

16. Mondal KC, Strydom AM, Tetana Z, Mhlanga SD, Witcomb MJ, Havel J, Erasmus RM, Coville NJ (2009) Boron-doped carbon microspheres. Mater Chem Phys 114(2):973-977. https://doi. org/10.1016/j.matchemphys.2008.11.008

17. Acharya CK, Li W, Liu Z, Kwon G, Heath Turner C, Lane AM, Nikles D, Klein T, Weaver M (2009) Effect of boron doping in the carbon support on platinum nanoparticles and carbon corrosion. J Power Sourc 192(2):324-329. https://doi.org/10.1016/j.jpows our.2009.03.020

18. Li X (2015) A modeling study of the pore size evolution in lithium-oxygen battery electrodes. J Electrochem Soc 162(8):A1636-A1645. https://doi.org/10.1149/2.0921508jes

19. Castanheira L, Silva WO, Lima FHB, Crisci A, Dubau L, Maillard $F$ (2015) Carbon corrosion in proton-exchange membrane fuel cells: effect of the carbon structure, the degradation protocol, and the gas atmosphere. ACS Catal 5(4):2184-2194. https:// doi.org/10.1021/cs501973j

20. Chesneau M, Beguin F, Conard J, Erre R, Thebault J (1992) The antioxidation effect of boron oxide on a pyrocarbon. Carbon 30(4):714-716. https://doi.org/10.1016/0008-6223(92)90190 $-8$

21. Hiroshi N, Kohsuke Y, Akira N, Sakuya T, Kensuke H (2013) Enhancement of electrical conductivity and electrochemical activity of hydrogenated amorphous carbon by incorporating boron atoms. J Phys Conf Ser 441(1):012042

22. Wagner P, Dickinson JM (1970) Ambient and high temperature experiments on boron-doped polycrystalline graphites. Carbon 8(3):313-320. https://doi.org/10.1016/0008-6223(70)90071-0

23. Song Z, Li L, Zhu D, Miao L, Duan H, Wang Z, Xiong W, Lv Y, Liu M, Gan L (2019) Synergistic design of a N, O co-doped honeycomb carbon electrode and an ionogel electrolyte enabling all-solidstate supercapacitors with an ultrahigh energy density. J Mater Chem A 7(2):816-826. https://doi.org/10.1039/C8TA10406A

24. Song Z, Zhu D, Li L, Chen T, Duan H, Wang Z, Lv Y, Xiong W, Liu M, Gan L (2019) Ultrahigh energy density of a N, O codoped carbon nanosphere based all-solid-state symmetric supercapacitor. J Mater Chem A 7(3):1177-1186. https://doi.org/10.1039/C8TA1 0158B

25. Young C, Kim J, Kaneti YV, Yamauchi Y (2018) One-step synthetic strategy of hybrid materials from bimetallic metal-organic frameworks for supercapacitor applications. ACS Appl Energy Mater 1(5):2007-2015. https://doi.org/10.1021/acsaem.8b001 03

26. Jones LE, Thrower PA (1991) Influence of boron on carbon fiber microstructure, physical properties, and oxidation behavior. Carbon 29(2):251-269. https://doi.org/10.1016/00086223(91)90076-U

27. Maldonado-Hódar FJ, Ferro-García MA, Rivera-Utrilla J, MorenoCastilla C (1999) Synthesis and textural characteristics of organic aerogels, transition-metal-containing organic aerogels and their carbonized derivatives. Carbon 37(8):1199-1205. https://doi. org/10.1016/S0008-6223(98)00314-5

28. Bang JH, Han K, Skrabalak SE, Kim H, Suslick KS (2007) Porous carbon supports prepared by ultrasonic spray pyrolysis for direct methanol fuel cell electrodes. J Phys Chem C 111(29):10959_ 10964. https://doi.org/10.1021/jp071624v

29. Liu J, Shao M, Tang Q, Chen X, Liu Z, Qian Y (2003) A medialreduction route to hollow carbon spheres. Carbon 41(8):16821685. https://doi.org/10.1016/S0008-6223(03)00143-X

30. Serp P, Feurer R, Kalck P, Kihn Y, Faria JL, Figueiredo JL (2001) A chemical vapour deposition process for the production of carbon nanospheres. Carbon 39(4):621-626. https://doi. org/10.1016/S0008-6223(00)00324-9

31. Haul R, Gregg SJ, Sing KSW (1982) Adsorption, surface area and porosity. 2. Auflage, Academic Press, London 1982. 303 Seiten, Preis: \$ 49.50. Berichte der Bunsengesellschaft für physikalische Chemie 86(10):957. https://doi.org/10.1002/bbpc.19820861019

32. Nerushev OA, Dittmar S, Morjan R-E, Rohmund F, Campbell EEB (2003) Particle size dependence and model for ironcatalyzed growth of carbon nanotubes by thermal chemical vapor deposition. J Appl Phys 93(7):4185-4190. https://doi. org/10.1063/1.1559433

33. Nyamori VO, Coville NJ (2007) Effect of ferrocene/carbon ratio on the size and shape of carbon nanotubes and microspheres. Organometallics 26(16):4083-4085. https://doi.org/10.1021/ om7003628

34. Li W, Lane AM (2009) Investigation of Pt catalytic effects on carbon support corrosion of the cathode catalyst in PEM fuel cells using DEMS spectra. Electrochem Commun 11(6):1187-1190. https://doi.org/10.1016/j.elecom.2009.04.001 
35. Wang H, Guo Q, Yang J, Liu Z, Zhao Y, Li J, Feng Z, Liu L (2013) Microstructural evolution and oxidation resistance of polyacrylonitrile-based carbon fibers doped with boron by the decomposition of B4C. Carbon 56:296-308. https://doi.org/10.1016/j. carbon.2013.01.017

36. Seah MP (1980) The quantitative analysis of surfaces by XPS: a review. Surf Interface Anal 2(6):222-239. https://doi. org/10.1002/sia.740020607

37. Kondo T, Kodama Y, Ikezoe S, Yajima K, Aikawa T, Yuasa M (2014) Porous boron-doped diamond electrodes fabricated via two-step thermal treatment. Carbon 77:783-789. https://doi. org/10.1016/j.carbon.2014.05.082

38. Li L-J, Glerup M, Khlobystov AN, Wiltshire JG, Sauvajol JL, Taylor RA, Nicholas RJ (2006) The effects of nitrogen and boron doping on the optical emission and diameters of single-walled carbon nanotubes. Carbon 44(13):2752-2757. https://doi.org/10.1016/j. carbon.2006.03.037

39. Yuan D, Chen J, Zeng J, Tan S (2008) Preparation of monodisperse carbon nanospheres for electrochemical capacitors. Electrochem Commun 10(7):1067-1070. https://doi.org/10.1016/j. elecom.2008.05.015

40. Ray SC, Tetana ZN, Erasmus R, Mathur A, Coville NJ (2014) Carbon spheres for energy applications: Raman and X-ray photoemission spectroscopy studies. Int J Energy Res 38(4):444-451. https ://doi.org/10.1002/er.3079

41. Ryu J, Suh Y-W, Suh DJ, Ahn DJ (2010) Hydrothermal preparation of carbon microspheres from mono-saccharides and phenolic compounds. Carbon 48(7):1990-1998. https://doi.org/10.1016/j. carbon.2010.02.006
42. Wang Q, Li H, Chen L, Huang X (2001) Monodispersed hard carbon spherules with uniform nanopores. Carbon 39(14):22112214. https://doi.org/10.1016/S0008-6223(01)00040-9

43. Sing KSW, Douglas DH, Haul RAW, Moscou L, Pierotti RA, Rouquerol J, Siemieniewska T (2008) Handbook of heterogeneous catalysis; Reporting physisorption data for gas/solid systems. Wiley

44. Petrov K, Rostami AA, Visintin A, Srinivasan S (1994) Optimization of composition and structure of metal-hydride electrodes. J Electrochem Soc 141(7):1747-1750. https://doi. org/10.1149/1.2054998

45. Zhao L, Wang Z-B, Sui X-L, Yin G-P (2014) Effect of multiwalled carbon nanotubes with different specific surface areas on the stability of supported Pt catalysts. J Power Sourc 245:637-643. https://doi.org/10.1016/j.jpowsour.2013.07.027

46. Zaldivar RJ, Kobayashi RW, Rellick GS, Yang JM (1991) Carborane-catalyzed graphitization in polyarylacetylene-derived carbon-carbon composites. Carbon 29(8):1145-1153. https:// doi.org/10.1016/0008-6223(91)90032-E

47. Kowbel W, Huang Y, Tsou H (1993) Effect of boron ion implantation on the oxidation behavior of three-dimensional carbon-carbon composite. Carbon 31(2):355-363. https://doi. org/10.1016/0008-6223(93)90040-H

Publisher's Note Springer Nature remains neutral with regard to jurisdictional claims in published maps and institutional affiliations. 